\title{
Study on the End Winding Inductance of Three-Phase Windings in Two Layers
}

\author{
Olivian CHIVER, Liviu NEAMT, Cristian BARZ, Eleonora POP, Cristinel COSTEA, Zoltan ERDEI
}

\begin{abstract}
This work addresses the issue of the accuracy with which the stator end winding inductance of A.C. machines is determined in the design stage. Only two-layer windings having a shortened pitch are treated in this paper. The end winding inductance was calculated by determining the distribution of the magnetic field, performing numerical analyses based on finite elements method (FEM). The manner of how the inductances are determined using the analysis results is described in the paper. For validating the procedure, comparisons between FEM results and laboratory tests were performed in case of one of the studied machine. There is a very good correlation between the results. Then, a comparative FEM-Analytical study was carried out. Own program was used to design and build the models necessary in the study. Based on about 130 models, some important conclusions have been depicted.
\end{abstract}

Keywords: A.C. machine; end winding inductance; FEM; two layers

\section{INTRODUCTION}

Usually, A.C. rotating electrical machines have a three-phase winding in the stator, and the currents which flow through every phase produce the rotating magnetic field. The total magnetic flux is compounded by the main magnetic flux, also called linkage flux and the leakage magnetic flux. The leakage flux at its turn includes the leakages of the notches (Fig. 1), the end winding leakages (Fig. 2), the differential leakages, and, in the case of large synchronous machines, the tooth-to-tooth leakages (Fig. 3).

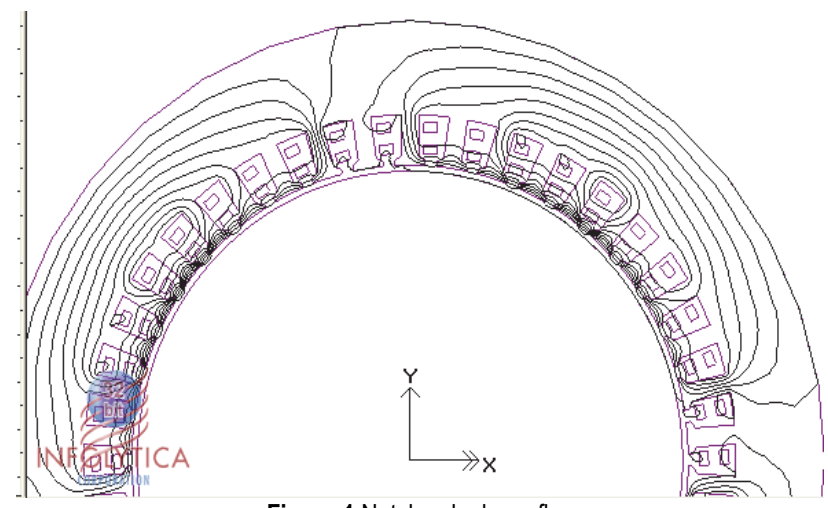

Figure 1 Notches leakage flux

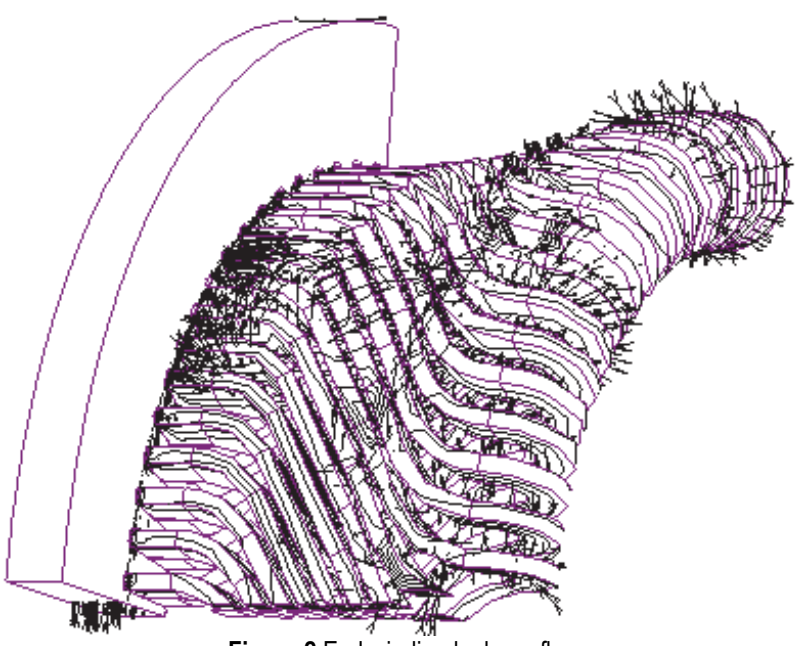

Figure 2 End winding leakage flux

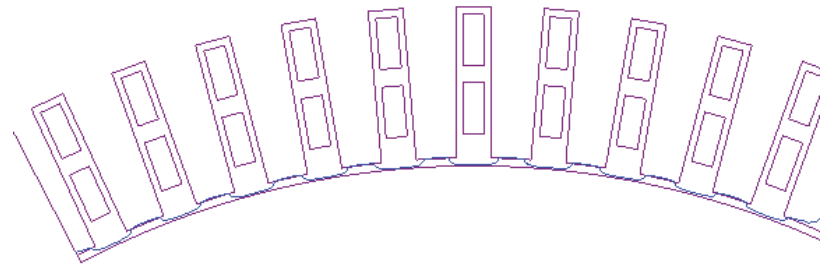

Figure 3 Tooth-to-tooth flux

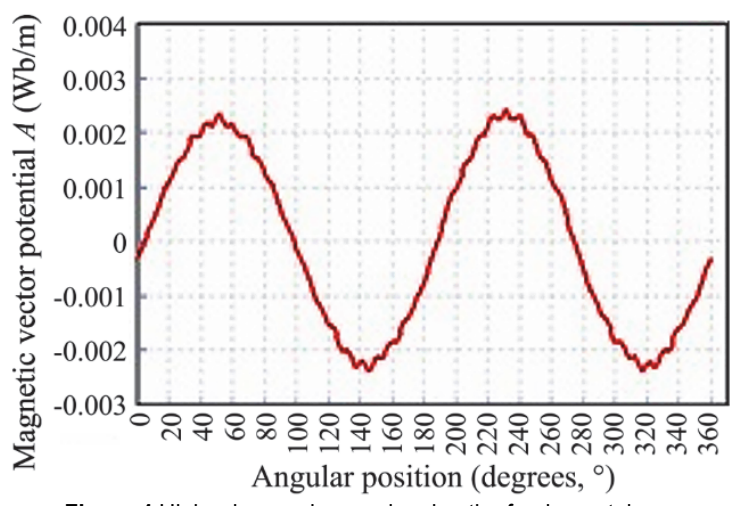

Figure 4 Higher harmonics overlapping the fundamental one

The differential leakages represent the magnetic fluxes corresponding to the higher harmonics which overlap the fundamental one (Fig. 4). These harmonics are caused especially by the magnetic circuit notches.

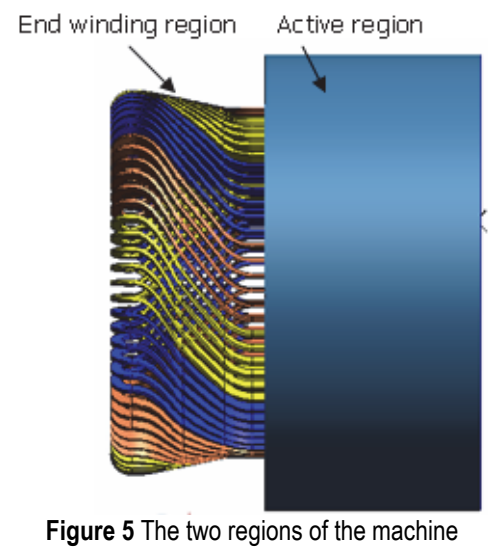

Three of the four types of leakage are located in the active part of the machine (Fig. 5), having a planar distribution in the cross-section. Only the end winding flux 
is located on the heads of the machine, around the coils end, and it has a truly 3D distribution.

The determination of all these leakages is necessary in order to compute the stator winding leakage inductance which represents one of the main machine parameters. This inductance is experimentally obtained as a whole, but in the design stage, it is computed as a sum of the mentioned four leakage inductances. It will be mentioned that the leakage inductance of the notches, the inductance of differential leakages, and tooth-to-tooth leakages inductance are analytically computed with great accuracy because the corresponding magnetic flux lines are planar in these areas. Instead, the magnetic flux lines in the end winding regions have a complicated 3D distribution, but the model used for analytical calculating of the corresponding inductance is very simplified. The discrepancy between the simplified and the real model provokes a large error in the determination of this inductance. The error can reach up to $50 \%$ [1].

This is why the paper is focused on the determination of this last inductance.

In order to calculate analytically the end winding inductance, improved approaches, with consideration of the 3D shape of the coils were presented in [2] and [3]. They used the solution of Neumann integral for inductance calculation and considered the influence of the ferromagnetic material. Some simplifications regarding the 3D shape of the coils were nevertheless necessary.

Laplace's equation is used in [4] in order to analytically calculate the magnetic vector potential and then the end winding inductance. In this paper, only a semicircular shape of the ends of the coils is considered.

The magnetic field distribution in end winding region is obtained using the edge element method in [5]. The 3D and 2D models are used in order to determine end winding inductance. Other papers [6]-[11] also show the use of numerical methods, of which the most widely used lately is FEM. The great advantage of this method consists in the possibility of solving complex systems with high accuracy in reasonable time.

The leakage inductance of the stator winding is experimentally determined by the removed rotor test. According to this method, the rotor is removed from the inside of the stator, and the stator winding is supplied from an adjustable A.C. voltage source, the stator currents being controlled. In the stator hole, a coil is placed in order to obtain the leakage magnetic flux. By this method, the whole leakage inductance is obtained, including end winding inductance and the leakage inductance from the active length of the stator.

In FEM simulations we will build the models as in experimental tests. The rotor will be removed. Two models of the machine stator are necessary in order to separate the end winding inductance from the active region of the stator leakage inductance: one $2 \mathrm{D}$, corresponding to the active region of the stator, and the other one $3 \mathrm{D}$, corresponding to the whole stator (active region plus end winding region). Because by FEM we determined separately the end winding inductance, the inner coil in the stator hole is not necessary in numerical models.

The end winding inductance is determined as the difference between 3D and 2D inductance [7]-[9].

\section{END WINDING INDUCTANCE DETERMINATION}

\subsection{Analytical Computation of the End Winding Inductance}

In design stage, the relation used for calculation of the end winding inductance is [12],

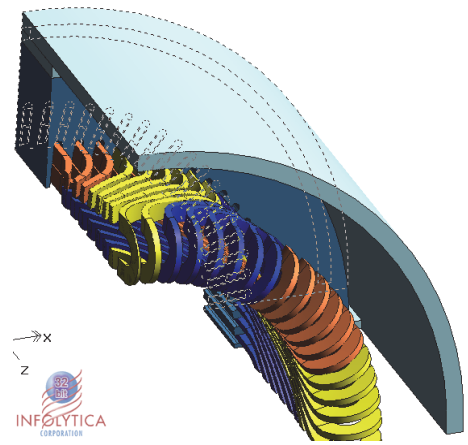

a) 3D model

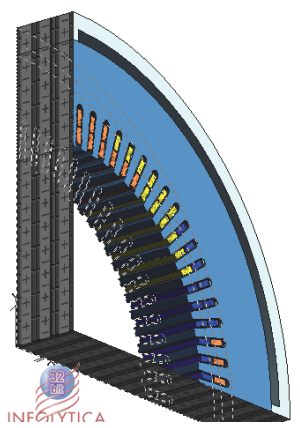

b) $2 \mathrm{D}$ model
Figure 6 Needed models

$L_{\mathrm{ew}}=0.68 \mu_{0} \frac{N^{2}}{p}\left(l_{\mathrm{ew}}-0.64 \beta_{y} \tau\right)$,

We noted: $L_{\mathrm{ew}}-$ end winding inductance; $N$ - number of turns per phase; $p$ - poles pairs number; $l_{\mathrm{ew}}-$ length of the coil ends; $\mu_{0}-$ air permeability; $\beta_{y}-$ relative pitch; $\tau-$ polar pitch.

The length of the coil ends has been determined based on the 3D numerical model, depending on the spatial coordinates of the coil end, for all built models. In this way, the same frontal length of the coils as in the $3 \mathrm{D}$ model is used for the analytical computation of the end winding inductance.

\subsection{FEM Simulations for the End Winding Inductance Determination}

As mentioned in section 1, for each studied machine, two numerical models were needed for end winding inductance determination. Fig. 6 shows these models for one of the designed machines. The models have the same currents, number of turns, and of course, the same length of the stator.

Because the models are without rotor, they have a constant magnetic permeability (they are unsaturated), and in this case, the inductance can be computed based on the stored magnetic energy. The end winding inductance is determined as the difference between the 3D inductance, $L_{3 \mathrm{D}}$, and $2 \mathrm{D}$ inductance, $L_{2 \mathrm{D}}$, both being computed based on the corresponding magnetic energy, $W$. The $3 \mathrm{D}$ and $2 \mathrm{D}$ analyses are by magneto-static type, the currents into phases being in relation (2) [13],

$\frac{I_{\mathrm{a}}}{2}=-I_{\mathrm{b}}=-I_{\mathrm{c}}$,

and the inductance, per phase, is computed with the relation (3) [7], [13],

$L=\frac{4 W}{3 I_{\mathrm{a}}^{2}}$ 


\section{FEM-EXPERIMENTAL COMPARISON}

In order to appreciate the accuracy of FEM simulations, we modelled an existing machine from our laboratory, and for this machine, we have experimentally determined the leakage inductance. Because in this case only the total leakage inductance can be experimentally obtained, we have compared this inductance.

The measurements have been performed on the stator winding of a synchronous generator having the following main data: four poles, a winding in double layer with 98 turns per phase and a shortened pitch of 9 notches, having a fractional number of notches per pole and phase 3,5, which means a number of 42 stator notches. Inner diameter has $245 \mathrm{~mm}$, outer diameter $365 \mathrm{~mm}$, active length 110 $\mathrm{mm}$, tooth width $8 \mathrm{~mm}$, polar shoe width $13,5 \mathrm{~mm}$, polar shoe height $2 \mathrm{~mm}$ and the notch height $21 \mathrm{~mm}$.

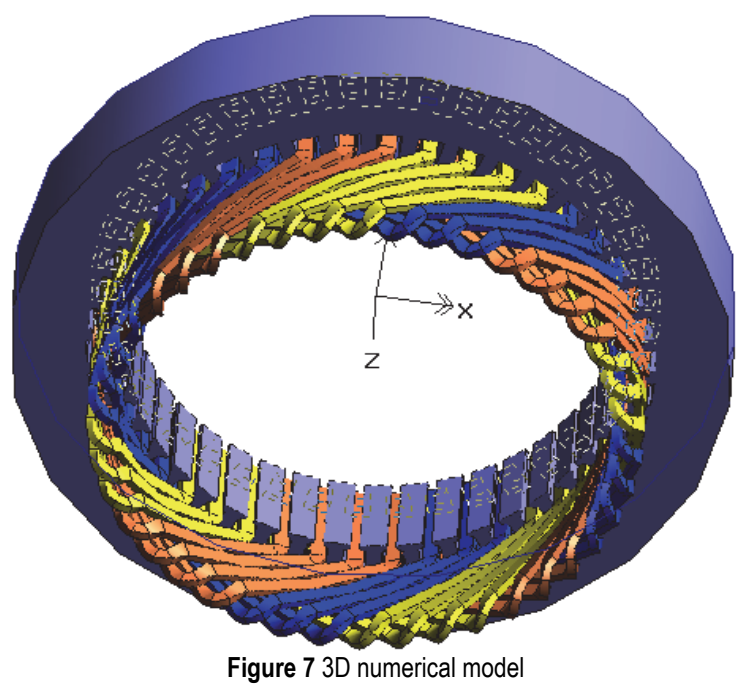

Fig. 7 shows the 3D numerical model corresponding to a half of the machine while Fig. 8 shows the machine during measurements.

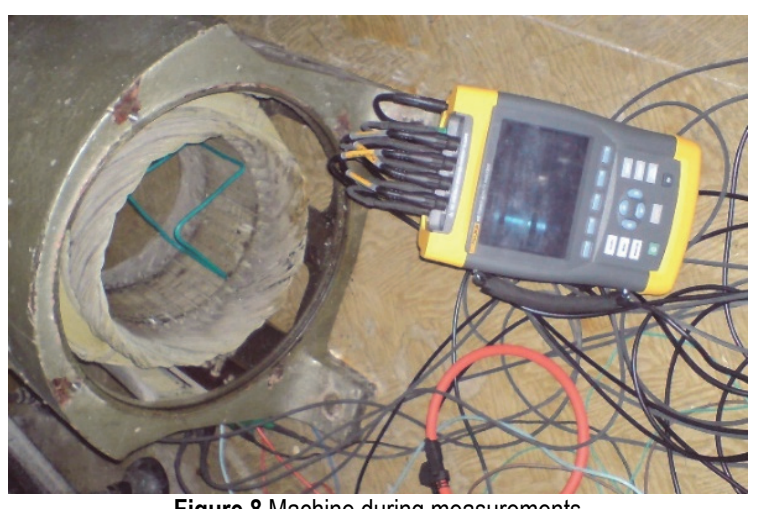

Figure 8 Machine during measurements

The coil from the inside of the stator bore (Fig. 8) is for determination of the useful magnetic flux, which closes through the rotor space when the rotor is removed. The inductance corresponding to this flux, $L_{\mathrm{b}}$, has to be subtracted from the total inductance and so we will get the leakage inductance. Measuring the inner coil voltage, $U_{\mathrm{b}}$, and the stator winding current, $I_{\mathrm{w}}$, the inductance is determined with relation (4) [14],

$$
L_{\mathrm{b}}=\frac{U_{\mathrm{b}}}{\omega I_{\mathrm{w}}} \frac{N k_{\mathrm{w}}}{N_{\mathrm{b}} \sin \frac{q^{\prime}}{3 q} \frac{\pi}{2}}
$$

In Eq. (4) we have been noted with: $N_{\mathrm{b}}$ - the number turns of the coil from the inside of the stator bore; $k_{\mathrm{w}}-$ the winding factor; $\omega$ - the angular frequency; $q^{\prime}-$ the highest integer number of notches included in the polar pitch; $q^{-}$ the actual number of notches per pole and phase.

In order to perform the measurements, a Fluke 435 apparatus has been used, and the measured values are shown in Tab. 1. In Tab. 2 are presented the results obtained by FEM and by measurements.

It can be pointed out that the value of the total leakage inductance obtained by FEM is very close to the experimentally determined one. A deviation of only $3 \%$ is very satisfactory.

Table 1 Measured values
\begin{tabular}{|l|c|c|c|}
\hline \multicolumn{1}{|c|}{ Quantities $\backslash$ phase } & A & B & C \\
\hline$U(\mathrm{~V})$ & 21,1 & 20,6 & 21,3 \\
\hline$I(\mathrm{~A})$ & 21,8 & 21,3 & 22 \\
\hline$P(\mathrm{~kW})$ & \multicolumn{3}{|c|}{0,468} \\
\hline$Q(\mathrm{kVAr})$ & \multicolumn{3}{|c|}{74,275} \\
\hline$U_{\mathrm{b}}(\mathrm{mV})$ & \multicolumn{3}{|c|}{} \\
\hline
\end{tabular}

Table 2 Inductances' values

\begin{tabular}{|l|c|c|}
\hline \multicolumn{1}{|c|}{ Inductance per phase } & Measured & FEM \\
\hline Total inductance $(\mathrm{mH})$ & 2,864 & 2,782 \\
\hline$L_{\mathrm{b}}(\mathrm{mH})$ & 0,986 & 0,957 \\
\hline Total leakage inductance $(\mathrm{mH})$ & 1,878 & 1,825 \\
\hline$L_{\mathrm{ew}}(\mathrm{mH})$ & - & 1,262 \\
\hline
\end{tabular}

\section{FEM-ANALYTICAL COMPARISON}

The main purpose of the paper is to study the accuracy of analytical determination of the end winding inductance. About 130 models have been designed and performed with our own program. These models with two-layer windings are of two types: with profiled (about 60 models) and round conductor (about 70 models) respectively.

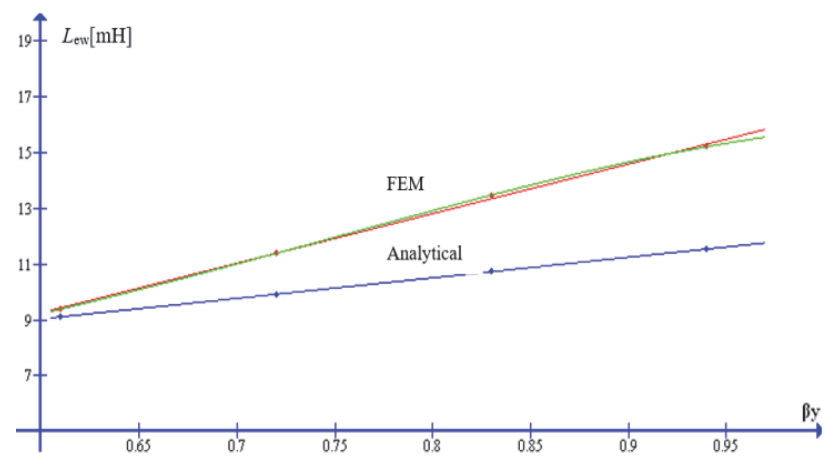

Figure $9 L_{e w}$ in function of the relative pitch in case of two-layer windings with profiled conductor for $500 \mathrm{~kW}, 6 \mathrm{kV}$, induction motor

The values of the end winding inductance obtained analytically and by FEM, in terms of the relative pitch, for one of the models, winding with a profiled conductor, are shown in Fig. 9, and in Fig. 10 the FEM/Analytical inductance ratio is presented. 


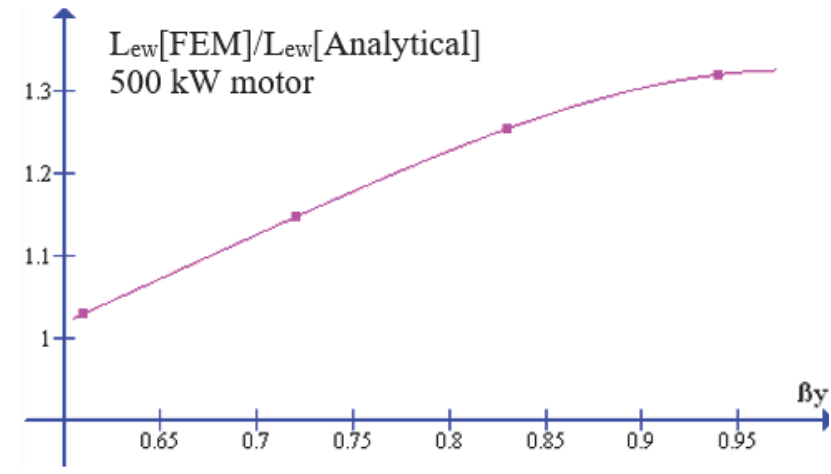

Figure $10 \mathrm{FEM}$ end winding inductance reported to the analytical ones in case of $500 \mathrm{~kW}, 6 \mathrm{kV}$ motor
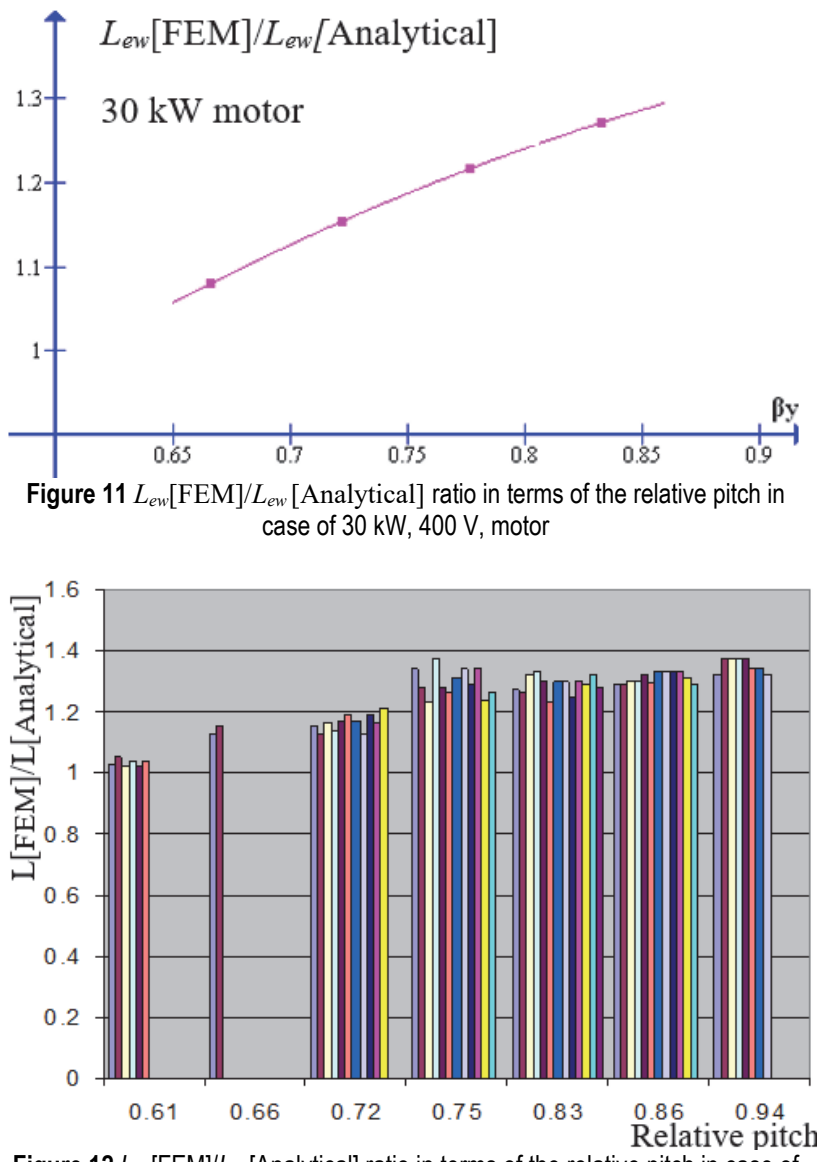

Figure $12 L_{e w}[F E M] / L_{e w}[$ Analytical] ratio in terms of the relative pitch in case of two-layer windings with profiled conductor

The same ratio, $L_{\mathrm{ew}}[\mathrm{FEM}] / L_{\mathrm{ew}}[$ Analytical] in case of low voltage $(400 \mathrm{~V}), 30 \mathrm{~kW}$ motor, is shown in Fig. 11.

For all models having winding made from profiled conductor, the $L_{\text {ew }}[\mathrm{FEM}] / L_{\text {ew }}$ [Analytical] proportion, in function of the relative pitch, is presented in Fig. 12.

Fig. 13 represents the average ratio in terms of the relative pitch for the same models.

It is noted that for all the models having windings by profiled conductor differences between the analytical calculated values and those determined by FEM were obtained.

These differences are small, even insignificant when the relative pitch is small (smaller than 0,65 ), and then they increase when the relative pitch increases. Taking the FEM values as reference, we recommend that the values determined analytically be increased to achieve results that are more accurate. So, in case of the windings with profiled conductor, having the relative pitch by $0,65-1$, the values computed analytically should be increased, proportional to the relative pitch, by $15-35 \%$.

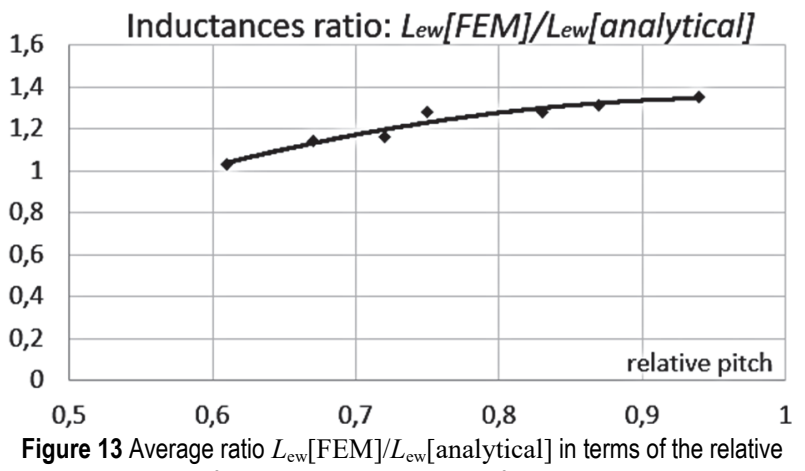
pitch for the analyzed models, profiled conductor

The FEM/Analytical inductance ratio in case of all models with windings by round conductor is shown in Fig. 14. Also for these machines, there are discrepancies between the values computed analytically and those determined by FEM. The discrepancies are greater when the relative pitch is greater. Unlike the profiled conductor windings, in case of the round conductor windings, deviations are important even in the case of a low relative pitch. So for this type of windings, only if the relative pitch is less than or equal to 0,5 , the end winding inductance determined analytically has enough accuracy. For a relative pitch between $0,55-1$, the values computed analytically should also be increased by $15-35 \%$, higher values for a larger relative pitch.

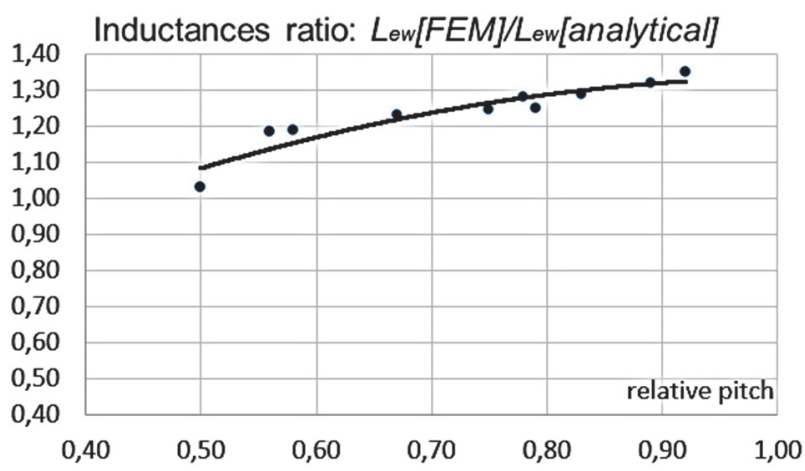

Figure 14 Average ratio of the inductances in case of round conductor, twolayer windings

\section{CONCLUSION}

The first main contribution of this paper is the achievement of a study regarding the accuracy of the analytical computation of the end winding inductance for two-layer, three-phase windings. The reference values are the ones determined by a FEM based method [7], unanimously accepted as having more accurate results than other possible methods to use (in design stage), and verified experimentally. Second, following the comparison, corrections of the analytical relationships are proposed for the analytical values to be closer to the simulated ones, which are, of course, considered more accurate. Without complicating the currently used analytical relationships, it was proposed to correct them with different percentages, depending on the relative pitch. 
However, it will be highlighted that the most accurate method of determination of the end winding inductance, even in the design phase, is that based on numerical simulations, as FEM. It can be argued that the precision of the results obtained with FEM depends, to a great extent, only on the accuracy of the performed numerical model. Once the model is correctly realised, the calculated values are close to the experimental ones.

\section{REFERENCES}

[1] Dordea, T. (1977). Electrical machines (in Romanian). Bucharest, Romania: Editura Didactică și Pedagogică.

[2] Ban, D., Zarko, D., \& Mandic, I. (2003, June). Turbogenerator end winding leakage inductance calculation using a 3-D analytical approach based on the solution of Neumann integrals. Paper presented at the IEEE International Electric Machines and Drives Conference, IEMDC'03, Madison, WI, USA. https://doi.org/10.1109/IEMDC.2003.1210661

[3] Schramm, A. \& Gerling, D. (2005, June). Analytical calculation of the end winding leakage inductance based on the solution of Neumann integral. Paper presented at the International Symposium on Industrial Electronics, Dubrovnik, Croatia. https://doi.org/10.1109/ISIE.2005.1529026

[4] Hsieh, M. F., Hsu, Y. C., Dorrell, D. G. \& Hu, K. H. (2007). Investigation on end winding inductance in motor stator windings. IEEE Transactions on Magnetics, 43(6), 25132515. https://doi.org/10.1109/TMAG.2007.896209

[5] Demenko, A., Nowak, L., \& Pietrowski, W. (2001). Calculation of end-turn leakage inductances of electrical machines using the edge element method.The International Journal for Computation and Mathematics in Electrical and Electronic Engineering, 20(1), 132-139. https://doi.org/10.1108/03321640110359813

[6] Davey, K. (2002). Predicting induction motor circuit parameters. IEEE Transactions on Magnetics, 38(4), 17741779. https://doi.org/10.1109/TMAG.2002.1017770

[7] Chiver, O., Micu, E., \& Barz, C. (2008, May). Stator winding leakage inductances determination using finite elements method. Paper presented at the $11^{\text {th }}$ International Conference on Optimization of Electrical and Electronic Equipment OPTIM'08, Braşov, România. https://doi.org/10.1109/OPTIM.2008.4602389

[8] Cox, T., Eastham, F., \& Proverbs, J. (2008). End turn leakage reactance of concentrated modular winding stators. IEEE Transactions on Magnetics, 44(11), 4057-4061. https://doi.org/10.1109/TMAG.2008.2002382

[9] Lin, R. \& Arkkio, A. (2009). Calculation and analysis of stator end-winding leakage inductance of an induction machine.IEEE Transactions on Magnetics, 45(4), 20092014. https://doi.org/10.1109/TMAG.2008.2010317

[10] Lin, R. \& Arkkio, A. (2008). 3-D finite element analysis of magnetic forces on stator end-windings of an induction machine. IEEE Transactions on Magnetics, 44(11), 40454048. https://doi.org/10.1109/TMAG.2008.2002379

[11] Tounzi, A., Henneron, T., Lemenach, Y., Askour, R., Dumetz, E. \& Piriou, F. (2004). 3-D approaches to determine the end winding inductances of a permanent-magnet linear synchronous motor. IEEE Transactions on Magnetics, 40(2), 758-761. https://doi.org/10.1109/TMAG.2004.825287

[12] Cioc, I. \& Nica, C. (1994). Designing electrical machines (in Romanian). Bucharest, Romania: Editura Didactică și Pedagogică.

[13] Bianchi, N. (2005). Electrical machine analysis using finite elements. Boca Raton, FL: CRC Press, Taylor \& Francis.
[14] Drăgănescu, O. G. (1987). Tests of rotating electrical machines (in Romanian). Bucharest, Romania: Editura Tehnică.

\section{Contact information:}

Olivian CHIVER, PhD Assis. Professor

Technical University of Cluj-Napoca,

Victor Babes, 62A, RO-430083 Baia Mare, Romania

olivian.chiver@cunbm.utcluj.ro

Liviu NEAMT, PhD Assis. Professor

Technical University of Cluj-Napoca,

Victor Babes, 62A, RO-430083 Baia Mare, Romania

liviu.neamt@cunbm.utcluj.ro

Cristian BARZ, PhD Assis. Professor

Technical University of Cluj-Napoca,

Victor Babes, 62A, RO-430083 Baia Mare, Romania

cristian.barz@cunbm.utcluj.ro

Eleonora POP, PhD Assis. Professor

Technical University of Cluj-Napoca,

Victor Babes, 62A, RO-430083 Baia Mare, Romania

eleonora.pop@cunbm.utcluj.ro

Cristinel COSTEA, PhD Assis. Professor

Technical University of Cluj-Napoca,

Victor Babes, 62A, RO-430083 Baia Mare, Romania

cristinel.costea@cunbm.utcluj.ro

Zoltan ERDEI, PhD Assis. Professor

Technical University of Cluj-Napoca,

Victor Babes, 62A, RO-430083 Baia Mare, Romania zoltan.erdei@cunbm.utcluj.ro 